\title{
"Yo, al contarle esto, no tengo porque mentir": identidades etnolingüísticas en las narrativas contadas por los migrantes de retorno nayaritas
}

"I have no reason to lie in telling you this": ethnolinguistic identities in the narratives of returned nayarita migrants

JOSÉ LUIS QUINTERO CARRILLO** jlquinterocarrillo@gmail.com

\footnotetext{
* Este artículo recoge los resultados de una investigación socializada en el XXVII Congreso Nacional y I Internacional de Lingüística, Literatura y Semiótica realizado en la Universidad Pedagógica y Tecnológica de Colombia, Tunja (9-12 de octubre de 2012).

** Docente de la Universidad Autónoma de Nayarit, México.
} 


\title{
Resumen
}

No hay razón para asumir que la narrativa de un individuo deba ser enteramente constante y verídica. La verdad en la construcción de una narrativa no es el problema primario. Al narrar sus experiencias de vida en los Estados Unidos, los migrantes retornados nayaritas asumen un punto de vista. Tales narrativas son producto de un doble proceso interpretativo, el suyo y el nuestro. Siempre será posible narrar los mismos acontecimientos de formas radicalmente diferentes, dependiendo de los valores y de los intereses del narrador, por ello la manera en que el narrador aborda esos acontecimientos complejos y preocupantes varía, porque recrear el pasado es una reconstrucción selectiva. Desde esta perspectiva, la construcción de la identidad de los migrantes nayaritas consiste en la creación narrativa de una imagen de sí mismos. Con el apoyo de los modelos de actitud presentados en los trabajos de Lambert y Lambert (1964); Fishman y Agheyisi (1970); Ajzen (1988) y López Morales (1989), trataremos de definir cuáles son esos rasgos característicos que contribuyen a crear la imagen de esa identidad.

Palabras clave: migración, narrativa, identidad, actitud, creencia.

\begin{abstract}
There is no reason to assume that the narrative of an individual is completely coherent and true. Truth is not a fundamental problem in the construction of a narrative. In narrating their experiences in the United States, Nayarita migrants who have returned assume a particular point of view. These narratives are the product of a double interpretation process, their own and ours. It will always be possible to narrate the same events in radically different ways, depending on the values and the interests of the narrator, for this reason way in which the narrator expresses these complex and disturbing events varies, because the recreation of the past is a selective reconstruction. From this perspective, the construction of identity in Nayarita migrants consists in the narrative creation of a self-image. Based on the research about attitudes in Lambert and Lambert (1964); Fishman and Agheyisi (1970); Ajzen (1988) and López Morales (1989), we will attempt to define which of these characteristic features contribute to creating an image of this identity.
\end{abstract}

Key words: migration, narrative, identity, attitude, belief. 


\section{Introducción}

Es posible que el ejemplo más acabado y prolongado de cultura migratoria de retorno se genere en el caso de mexicanos que regresan de los Estados Unidos. En todo caso, en términos cualitativos y cuantitativos, es el fenómeno de migración más estudiado. Todavía hoy, persisten los códigos compartidos que acuñó la cultura migratoria desde finales del siglo XIX, a ambos lados de los más de tres mil kilómetros de frontera que comparten ambos países.

El estado de Nayarit, entidad en donde se llevó a cabo esta investigación, está enclavado en la región mexicana con mayor tradición migratoria, junto a los estados de Zacatecas, Jalisco, Guanajuato, Michoacán y Colima, en el occidente de México. Durante muchos años, a pesar de las fuertes restricciones fronterizas ${ }^{1}$, se ha consolidado un circuito migratorio con los Estados Unidos del que participan los miles de migrantes temporales mexicanos que regresan cíclicamente a sus comunidades de origen. Es un fenómeno de no poca importancia que merece ser ilustrado por el indudable impacto socioeconómico que tiene en el nivel individual, familiar, comunitario y nacional, a uno y otro lado de la frontera.

Es importante mencionar que la reciente crisis económica de los Estados Unidos ha obligado a volver a miles de mexicanos, muchos de ellos migrantes nayaritas, a sus comunidades de origen. Su retorno forma parte de la nueva realidad social del estado de Nayarit. En la gran mayoría de los casos, sin embargo, no vuelven solos, con ellos regresa el núcleo familiar conformado también por hijos que nacieron en tierras estadounidenses.

\footnotetext{
De 1965 a la fecha, la llamada "era de los indocumentados" se ha caracterizado por un clima de tensión en la zona fronteriza y la radicalización de las leyes estadounidenses, que han desembocado recientemente en la aprobación de la polémica iniciativa de ley HR4437 "Acta de Protección Fronteriza, Antiterrorismo y Control de Inmigración Ilegal" ("Border Protection, Antiterrorism and Illegal Immigration Control Act"), mejor conocida como Ley Sensenbrenner, que establece la deportación inmediata de los indocumentados que lleven en el país menos de dos años, la tipificación como criminales de quienes ayuden a ingresar a los "ilegales" y la construcción del cercado triple (Secure Fence Act) de un muro de 1,126 kilómetros en la frontera. (Luna, 2002, p. 256).
} 
En las "narrativas de frontera"2 captadas durante las entrevistas, los migrantes retornados nayaritas dejaban constancia del final de "el sueño americano". Para ellos, el país de las oportunidades había quedado atrás y ahora volvían a sus comunidades, en muchos casos sin empleo, sin casa propia, sin arraigados referentes socioculturales, en un momento crucial para la historia familiar de cada uno de sus integrantes.

La manera en que el migrante-narrador aborda los acontecimientos complejos y preocupantes del retorno varía, porque recrear el pasado inmediato es una reconstrucción selectiva. Es natural, entonces, que los retornados nayaritas excluyan de sus narrativas las experiencias que minan las identidades que en el momento de la entrevista deseaban destacar.

\section{Metodología de la investigación}

Dentro del extenso abanico de lo que conocemos como investigación cualitativa, la etnometodología ${ }^{3}$ ha resultado fundamental para el estudio de las interacciones humanas en situaciones sociolingüísticas específicas. Así pues, para los intereses de esta investigación, el uso de las técnicas cualitativas debe entenderse como una forma de acercarnos a la realidad actual de la migración méxico-estadounidense desde una zona geográfica específica en el occidente del país, el estado de Nayarit.

En ese sentido, el uso de los géneros discursivos primarios ${ }^{4}$ entre los que se cuenta la entrevista, tiene gran importancia en la construcción narrativa de la identidad lingüística, porque a través de ella se logra un fuerte efecto de proximidad en la reconstrucción de las experiencias a través de las formas cotidianas del lenguaje.

En los últimos años, el estudio de la lengua en el ámbito social se ha caracterizado por examinar la experiencia humana intentando analizar las historias de hombres y mujeres concretos. En esa dirección, nuestra investigación propuso la utilización de las llamadas

2 Al formular el sintagma "narrativas de frontera" queremos hacer referencia a la producción de un tipo particular de narraciones que cuentan las experiencias de los migrantes retornados, organizadas en una trama argumental, y enmarcadas en unas coordenadas espacio-temporales específicas. (Quintero, 2010).

3 Usamos el término etnometodolgía para referirnos a "la investigación de las propiedades racionales de las expresiones contextuales y de otras acciones prácticas como logros continuos y contingentes de las prácticas ingeniosamente organizadas de la vida cotidiana". (Garfinkel, [1968] 2006, p. 20).

4 Es importante el aporte de Bajtín ([1979] 1982) en lo que respecta a su concepto de género discursivo. Bajtín distingue entre géneros discursivos primarios y secundarios: los segundos surgirían de condiciones de comunicación cultural más compleja, que para desarrollarse, deben absorber muchos discursos primarios surgidos desde la comunicación inmediata. 
"historias de vida" para explorar las trayectorias de vida de los migrantes colimenses obtenidas mediante entrevistas.

William Labov ([1972] 1984, p. 29) pondera el uso de las entrevistas, en el sentido de que son un excelente medio de hacer acopio de "habla" para realizar un análisis cualitativo. La técnica de la entrevista sociolingüística se ha venido replanteando desde la perspectiva de la obtención de datos linguísticos, que puede ser a través de conversaciones espontáneas o, como es nuestro caso, a través de conversaciones semidirigidas.

Para Mejía Navarrete (2004), "la particularidad de las historias de vida es un proceso creativo de indagación exhaustiva, que consiste en la aplicación de la técnica cualitativa con un alto nivel de adaptación e invención a cada momento del orden cronológico" (p.292). En efecto, el proceso creativo y de interacción personal que produjo en los informantes entrevistados el uso de la entrevista semidirigida la convirtió en una técnica ideal para alcanzar un mayor nivel de persuasión y armonía con los migrantes nayaritas retornados. La investigación que da lugar al presente trabajo se basa en un corpus de 15 entrevistas realizadas entre los meses de noviembre de 2011 y mayo de 2012 en los municipios de Tepic, Xalisco, Santiago e Ixtlán del Río, en el estado de Nayarit, México. De las 15 entrevistas, 10 corresponden a migrantes de retorno definitivos y cinco a migrantes de retorno temporales ${ }^{6}$ que viajaban a su comunidad por estancias cortas que variaban entre los quince días y los tres meses.

\section{El valor de verdad en la construcción de la identidad narrativa}

No hay razón para asumir que la narrativa de un individuo deba ser enteramente constante y verídica. Como todos, los migrantes nayaritas retornados experimentan huecos significativos en el recuerdo de sus historias, de tal manera que estas son el resultado de los "focos" de memoria activos. (Chafe, 1980).

En sentido estricto, nuestro estudio de las narrativas de frontera es dirigido, no por la exigencia de verificación ordinaria, sino por un criterio de verosimilitud. Es decir, las historias de los

\footnotetext{
Según Silva-Corvalán (2001, p. 60), la entrevista semidirigida parte de una estructura previa que se puede ir adecuando en el momento mismo de su realización introduciendo tópicos, preguntas, o comentarios propicios que puedan ser de interés para los fines de la investigación.

6 La circularidad del fenómeno de migración México-Estados Unidos se define en términos de una estancia temporal en los EE. UU. que les permite a los migrantes trabajar y regresar después de un período de tiempo relativamente corto a sus lugares de origen. El Instituto Nacional de Estadística, Geografía e Informática en México (INEGI), se basa en un criterio durativo, medido en periodos de hasta cinco años, para considerar temporal el retorno migratorio.
} 
migrantes retornados no se componen de un sistema de asuntos verificables, en el sentido general del término, sino que se construyen como narrativas, y como tales deben ser analizadas ${ }^{7}$.

Desde esta perspectiva, la construcción de la identidad de los migrantes nayaritas consiste en la creación narrativa de una imagen de sí mismos. Con el apoyo de los modelos de actitud presentados por Lambert y Lambert (1964), Fishbein (1966), Fishman y Agheyisi (1970) y López Morales (1989), trataremos de definir cuáles son esos rasgos característicos que contribuyen a crear la imagen de esa identidad.

Para Lambert y Lambert (1964), la actitud estaría compuesta por tres rasgos: el cognoscitivo, en donde se incluyen las percepciones, las creencias y los estereotipos presentes en el individuo; el afectivo, en donde se hace referencia a las emociones y a los sentimientos; y el conativo, que se describe en términos de actuar y reaccionar de una determinada manera con respecto a un objeto.

Fishbein (1966) añade la noción de creencia, modificando la posición multicomponencial. Fishbein introduce la distinción entre actitud y creencia. Para él, la actitud estaría compuesta solamente por lo afectivo, en tanto que la creencia estaría integrada por dos rasgos: el cognoscitivo y la disponibilidad para la acción.

Por su parte, López Morales (1989) advierte que en los modelos de Lambert y Fishbein hay varios denominadores comunes: "las actitudes son adquiridas, permanecen implícitas, son relativamente estables, tienen un referente específico, varían de dirección y grado, y proporcionan una base para la obtención de datos" (p. 234). De acuerdo con las semejanzas y diferencias que comparten esos modelos de actitud, él propone un modelo en el que las relaciones entre creencias y actitudes se reflejan de la siguiente forma (figura 1).

Según este modelo, las creencias estarían dominadas por un solo rasgo, el conativo. Como puede observarse, López Morales ubica en distintos niveles los conceptos de "creencia" y "actitud". Las creencias, en este modelo, darían lugar a actitudes diferentes y, a su vez, las

\footnotetext{
Uno de los migrantes retornados entrevistados, Roberto, expresaba, en tono casi confesional, su necesidad de hacer verificable lo contado: "yo lo que // sobre mis experiencias // son las que yo he vivido / otras gentes han vivido tal vez peores / o mejores // ¿verdad? pero:: // yo en lo personal:: / yo al contarle esto // yo no tengo por qué mentir // porque son cosas // que / que son:: // experiencias mías personales y que:: / no cualquier gente la sabe // la sabe mi esposa y hoy en día usted // y el muchacho aquí presente". Consultar al final del artículo las convenciones de transcripción.
}

\section{6}




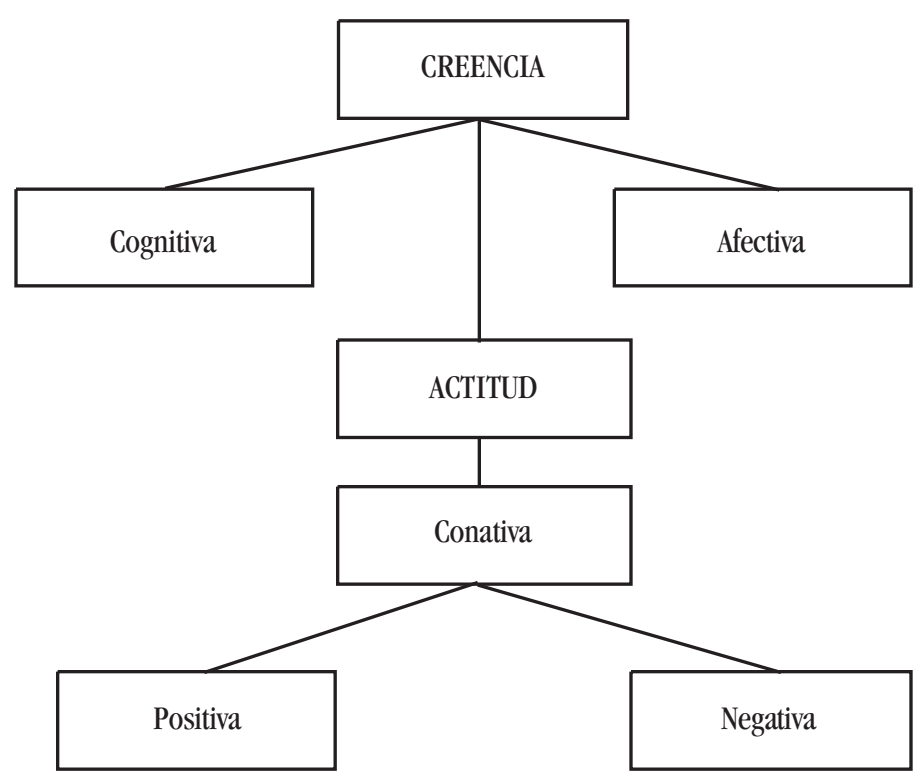

Figura 1. Modelo de López Morales.

actitudes, junto a los elementos cognitivos y afectivos, ayudan a conformar las creencias. "Las creencias pueden estar basadas en la realidad pero en gran medida no aparecen motivadas empíricamente". (López Morales, 1989, pp. 235-236).

Además, López Morales (1989) introduce dos conceptos que resultan trascendentes a la hora de valorar una actitud. "Las actitudes sólo pueden ser positivas, de aceptación, o negativas, de rechazo; una actitud neutra es imposible de imaginar (pensando en su naturaleza conativa): se trata más bien de ausencia de actitud" (pp. 234-235).

\section{Análisis de resultados}

Por motivos de espacio, para facilitar el análisis y seguir una estructura homogénea, hemos seleccionado dos fragmentos narrativos agrupados en dos vertientes: la primera, que reconozca las identidades etnolingüísticas de los migrantes retornados en cualquiera de los dos contextos, el mexicano o el estadounidense; y una segunda, que atienda a las identificaciones culturales que asumen los migrantes nayaritas en sus historias. 


\subsection{Identidades etnolingüísticas de los migrantes retornados}

La pertenencia étnica no es un concepto fácil de asir. Entre los estudiosos de los fenómenos identitarios hay poco consenso sobre cómo definirla y dentro de cuál disciplina ubicarla. Igualmente, las posiciones con respecto a la relación entre la pertenencia o identidad étnica y la lengua son también diversas. Por ejemplo, Gumperz y Cook-Gumperz (1982, p. 7) sostienen una posición crítica cuando señalan que la identidad y la pertenencia étnica son, en gran medida, establecidas y mantenidas por la lengua. Haarmann (1986, p. 20) apoya esta postura solo en parte, cuando señala que la relación entre la lengua y la pertenencia étnica se debe ver solamente en el sentido de que la lengua afecta a la pertenencia étnica. De acuerdo con la Teoría de la Identidad Social de Tajfel (1974) y la Teoría de la Identidad Etnolingüística de Giles y Johnson (1987), parece claro que la lengua desempeña un papel fundamental en la formación y la preservación de la identidad etnolinguística de un grupo social. A su vez, la identidad etnolinguística también se relaciona con las actitudes de la lengua.

En la siguiente narrativa, Roberto, un migrante de retorno nayarita que ahora radica en la ciudad de Tepic, cuenta una situación de discriminación lingüística que vivió en los primeros días de su llegada a los Estados Unidos, por no saber inglés. Experiencias similares le han servido para cambiar su actitud hacia esa lengua, con respecto a sus creencias originales.

\footnotetext{
Roberto: "estaba tratando de aprender inglés // y estaba una persona que:: / pues a la vista se mira que es / paisano // y:: // pues me dirigí a:: ordenar algo para:: una hamburguesa o algo así / yo no podía:: / pronunciar / papas fritas ¿me entiendes? / no podía / pronunciar papas fritas entonces le dije / le dije "dame:: unas // \{(L2) fried crisps\} / con una \{(L2) hamburger\}" así pero:: lo dije:: // así todo mocho ¿edá? le dije // entonces / se agarró riendo la persona / entonces le digo "¿por qué te ríes?" // y pero:: // me dice "yo no hablo / español" / o sea él me decía:: en inglés // entonces ya cuando:: ahí como pude:: / dije lo que dije para ordenar para todos // y luego me dice "¿qué vas a querer de tomar?" // entonces me dio mucho coraje // en ese instante // [...] era algo fuerte para mí porque:: te entra una frustración tremenda // una frustración muy tremenda / y// en este tiempo:: // ahí donde vivía pos había mucho americano y:: // había bastante mexicano y otras razas // de Latinoamérica pero:: // pues te separas / te segregas tú con tu:: // tu gente y ellos con su gente y luego entra lo del racismo y:: // muchas cosas de pro- por medio que:: / son cosas que me pasaron //"8.
}

La creencia que se infiere del relato de Roberto es que el no saber inglés puede acarrearle consecuencias negativas. El elemento cognitivo se basa en un hecho objetivo, la mala experiencia que sufrió Roberto en un restaurante por su desconocimiento del idioma inglés. El no saber esa lengua le ocasionó efectos negativos que se evidenciaron en las actitudes expresadas en su propia conducta y en la de los demás: aislamiento, segregación y racismo. En el nivel afectivo, Roberto se dice afectado por un sentimiento de frustración tremendo. De acuerdo al modelo anterior, estas implicaciones pueden expresarse en el siguiente esquema (figura 2).

8 Consultar al final del artículo las convenciones de transcripción. 


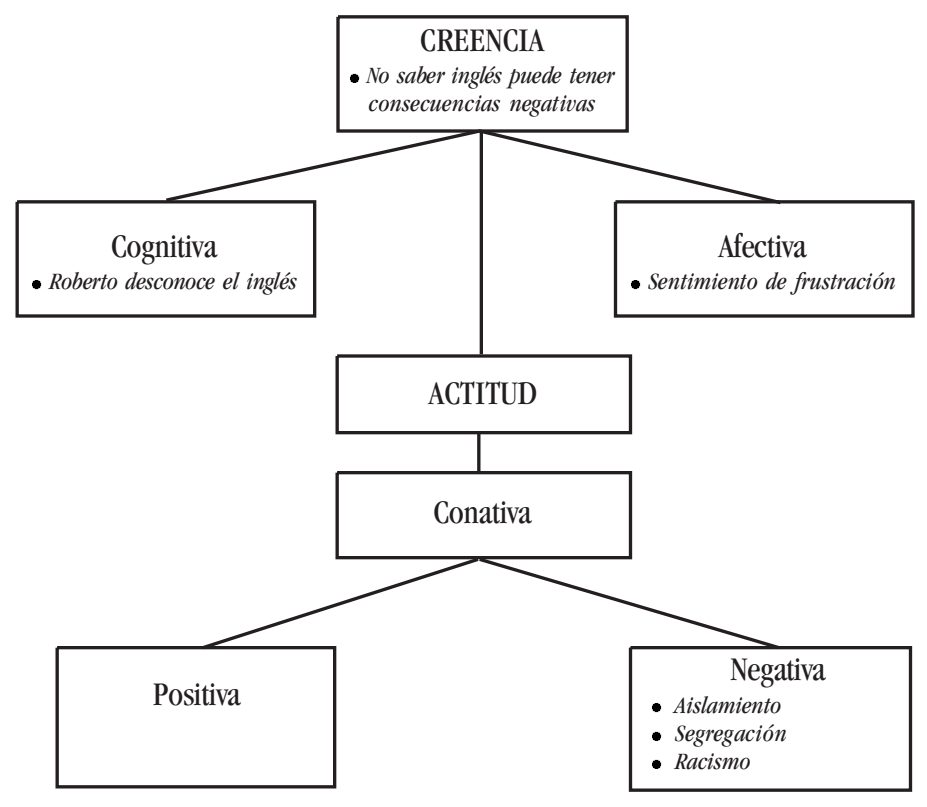

Figura 2. "Roberto no sabe inglés".

Es importante advertir que, para reproducir el inglés, Roberto utiliza el estilo directo, lo que da una idea de la importancia que reviste para él la situación de molestia, primero, y de frustración, que tuvo posteriormente. En cuanto a las conductas de aislamiento, segregación y racismo que sufre Roberto, implican que se pueden traducir en un cambio positivo conforme aumente el uso de la lengua que desconoce, el inglés.

Se puede considerar que, desde un punto de vista sociolingüístico, en la narrativa de Roberto se manifiesta una situación de prestigio social y lingüístico de la lengua local, el inglés, sobre su propia lengua, el español. Conforme a su argumentación narrativa, la jerarquía de una lengua sobre la otra también puede establecerse a nivel sociocultural, cuando afirma: "pues te separas / te segregas tú con tu:: // tu gente y ellos con su gente".

Esta representación subjetiva de su identidad individual se entiende como una representación interna de la imagen que Roberto tiene de sí mismo. Dicha representación le sirve para identificarse con los miembros de su grupo étnico -al que él llama "la raza mexicana"- y constituye su "yo mismo" colectivo que lo distancia del endogrupo dominante ${ }^{9}$, representado por los estadounidenses.

9 De acuerdo con Tajfel ([1981] 1984, p.168), una actitud favorable del endogrupo, conjuntamente con el comportamiento deseable de los miembros típicos del exogrupo, promoverá el desarrollo de una buena relación interpersonal, mientras que una actitud desfavorable del endogrupo, con el comportamiento indeseable de los miembros del exogrupo, impedirá el progreso adicional de la relación. 
A este respecto, algunos autores han señalado que las comunidades hispanas en los Estados Unidos parecen experimentar mayores problemas de aculturación. Silva-Corvalán (2000) afirma que, pese a la escasez de estudios científicos "se culpa a menudo, sin apoyo empírico confiable, al bilingüismo, con o sin dominio completo del inglés, de ser la causa de los males sociales que aquejan a grandes grupos de hispanos" (p. 76).

Sin embargo, para otros investigadores el proceso de sustitución lingüística del español por el inglés, parece evidente, a partir de la segunda y tercera generación. Portes y Hao (2001) afirman que los Estados Unidos son un "auténtico cementerio de lenguas extranjeras, en el que el conocimiento de las lenguas maternas de cientos de grupos de inmigrantes rara vez se prolonga más allá de la tercera generación. En ningún otro país es tan rápido el proceso de asimilación lingüística ni el paso al monolingüismo" (p. 58).

De cualquier forma, lo que parece claro es que el fenómeno de la migración mexicana a los Estados Unidos representa uno de los aspectos en los que la cuestión de las identidades etnolingüísticas se expresa con mayor fuerza. En estos desplazamientos no pueden dejarse de lado las expresiones culturales y la cuestión de la permanencia en las formas y en las concepciones de vida de quienes se ven inmersos en las diferentes experiencias migratorias.

Es posible afirmar que, en lo que toca a la cuestión de las identidades y de la cultura, Roberto, de manera casi inevitable, elabora sus percepciones de tipo identitario a través de procesos sincréticos. Él, como casi todos los migrantes retornados, se encuentra sometido a procesos de aculturación y transculturación, de reinterpretación y apropiación etnolingüística.

\section{Identificaciones culturales de los migrantes retornados}

Llamaremos "identificaciones culturales" al conjunto de prácticas y valores que dan sentido de inclusión o exclusión a un grupo social determinado. En el conjunto de prácticas relevantes podemos incluir lo que hacemos, cómo lo hacemos, nuestra conducta y nuestros dispositivos indicadores de pertenencia grupal. En tanto, los valores relevantes incluyen lo que nos gusta y desagrada, lo que nos importa, lo que disfrutamos, lo que hacemos excepcionalmente, lo que consideramos que son nuestros ideales. (Coupland, Garret y Williams, 2005, p. 72).

Una cultura es, por tanto, un conjunto de prioridades y tolerancias sobre lo que hacemos y lo que valoramos, que invocamos para construir una identidad social compartida y distinguirla de otras identidades. 
En cuanto a la relación entre lengua y cultura, Giles y Johnson (198, p. 241) sostienen que la lengua realiza por lo menos cuatro funciones psicolingüísticas en cuanto a la pertenencia étnica:

- La lengua es un elemento discriminador para medir la calidad de un miembro dentro de un grupo étnico particular.

- La lengua tiene un carácter prominente en la clasificación interétnica.

- La lengua es un aspecto relevante de la identidad étnica.

- La lengua es un medio ideal para facilitar la cohesión intergrupal.

Desde la perspectiva de estos autores, en el plano de las identificaciones culturales, podemos ubicar las prácticas y valoraciones que los migrantes retornados hacen de sí mismos -a uno y otro lado de la frontera- en dirección al grupo o grupos con los que se relacionan. Esta escala de valoraciones y conocimientos se establece a partir de apreciaciones de tipo sociocultural que pueden reflejarse en los niveles afectivo, conativo y cognitivo del modelo de actitud propuesto por López Morales, como veremos en la narrativa siguiente.

Desde la perspectiva de estos autores, en el plano de las identificaciones culturales, podemos ubicar las prácticas y valoraciones que los migrantes retornados hacen de sí mismos -a uno y otro lado de la frontera- en dirección al grupo o grupos con los que se relacionan. Esta escala de valoraciones y conocimientos se establece a partir de apreciaciones de tipo sociocultural que pueden reflejarse en los niveles afectivo, conativo y cognitivo del modelo de actitud propuesto por López Morales, como veremos en la narrativa siguiente.

\section{1. "Elisa se va de casa"}

Elisa no es propiamente una migrante de retorno, pero año con año visita el pueblo de sus padres, Ixtlán del Río, Nayarit. La razón de incluirla en este artículo es contrastar su caso con el de los migrantes mexicanos de primera generación. Ella nació en los Estados Unidos y es hija de padres mexicanos. Posee, por lo tanto, la doble ciudadanía. Su familia vive en Los Ángeles. Elisa, por decisión propia, se ha mudado a San Diego para continuar con sus estudios. Tiene 22 años y trabaja en un laboratorio biogenético. Vive sola, en una especie de lucha diaria contra los relojes y los horarios laborales. En su narrativa, manifiesta el sentido de su pertenencia étnica, no ya como propiedad de un grupo, sino como un modelo pluralista en el que los individuos llevan su pertenencia étnica consigo, en sus interacciones con los miembros de otros grupos. 
José Luis Quintero Carrillo

Elisa: este:: / pos me salí de la casa por / para eeh / para estudiar // no fue por otra razón este / allá se usa que tú vas y:: te internas a:: eeh a la universidad // y este:: y esa fue la decisión es la escuela esa que escogí que / está en San Diego / este fue muy buena / es / una escuela muy buena / este:: y dije "no pos dos horas no está lejos de con mis papás" // y este:: // pos la experiencia estuvo / pos muy bien digo / eeh te enseña muchas cosas estar / fuera de casa / ( tos de fondo) te enseña a ser responsable te enseña a ser / este:: // no sé cómo / no libre tampoco pero te enseña a / te enseña muchas cosas de la vida que / que tú no la ves cuando estás en la casa // y pos /

E.: ¿̨te sientes más libre? //

Elisa: pos libre en el aspecto que:: // que pos no tengo que:: / que este // ¿cómo se dice? (se dirige en voz baja a su hermana) / como / no me tengo que:: / no tengo que depender a nadie yo sola:: / si tengo que ir a hacer esto pues yo voy / si tengo que hacer lo otro yo voy / no necesito depender "jah! papi ¿me lleva?" "jah! mami ¿me lleva?" // sola este / hago lo que tengo que hacer //

En este ejemplo, las creencias de Elisa se basan en la identificación de ciertos usos y costumbres de la cultura estadounidense, "allá se usa que tú vas y:: te internas a:: eeh a la universidad //"10. Sin embargo, en el nivel afectivo, para Elisa es muy importante conservar los lazos familiares. En el aspecto conativo destacan su sentido de la responsabilidad; su aspiración de lograr la independencia familiar; y el grado de satisfacción y de enseñanzas positivas que ha traído consigo la experiencia de vivir sola.

Para tramitar su propia identidad, Elisa debe negociar las diferencias culturales que persisten entre su mundo familiar - de arraigadas costumbres mexicanas- y el estilo de vida estadounidense -que promueve la realización individual-, de tal manera que las creencias familiares puedan conciliarse con su nueva realidad social. En la construcción de una representación de sí misma, Elisa trata de integrar en su biculturalidad lo que proyecta ser. Por un lado, desea mantener los lazos familiares que reproducen sus identificaciones culturales con México; por el otro, intenta romper con las viejas tradiciones que fomentan la dependencia femenina en muchas de las familias mexicanas. En la figura 3 se reflejan esas representaciones.

10 El ejemplo de Elisa puede servir para documentar la dificultad, ya advertida por López Morales, de diferenciar a veces las creencias de los hechos. Esto es así, afirma López Morales (1989, p. 235), porque "normalmente los hablantes no distinguen entre creencia y hecho, sino que actúan como si sus creencias fuesen hechos". 


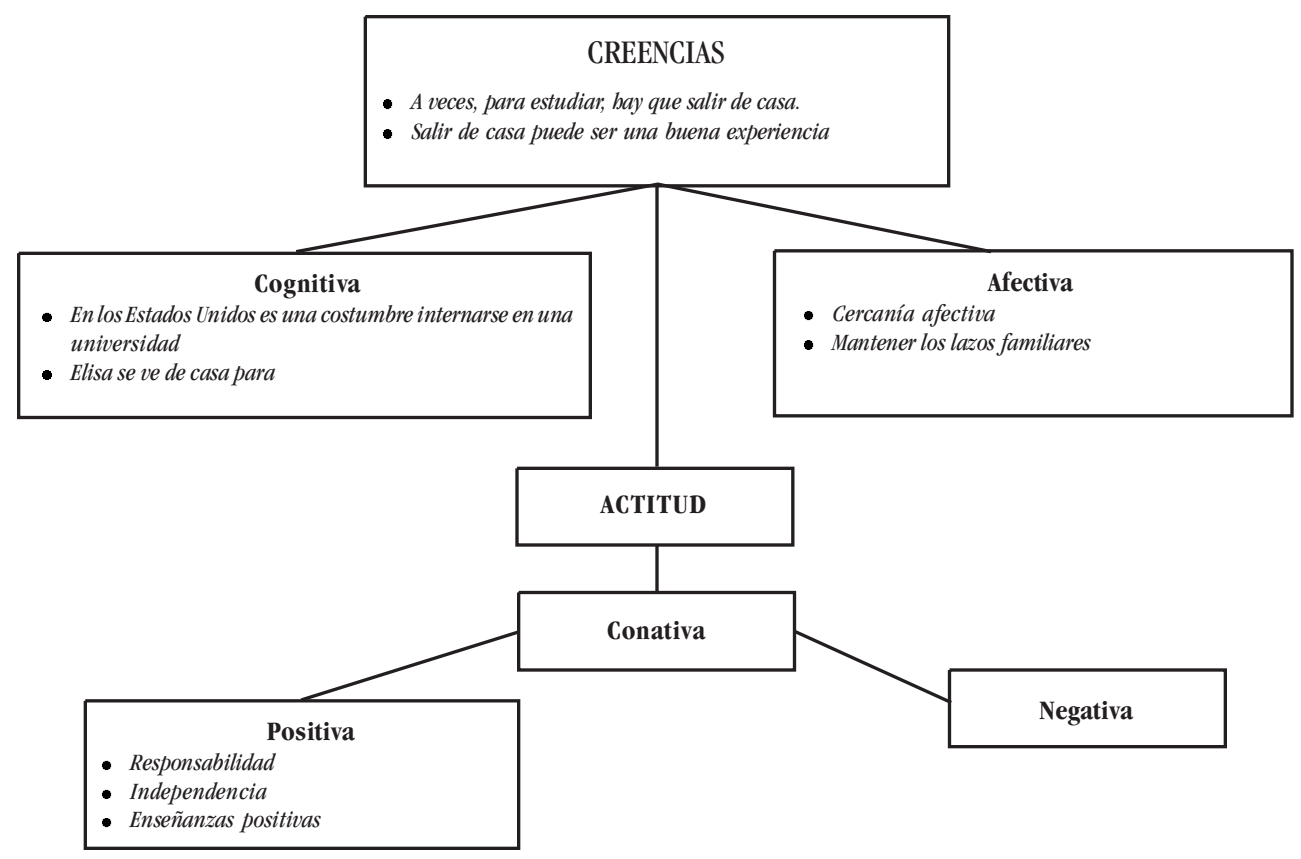

Figura 3. "Elisa se va de casa".

Para Elisa, el redescubrimiento de su identidad étnica es parte de un proceso de autogestión, en un contexto más amplio. Esta "nueva" pertenencia étnica, bicultural, es una actitud interna que la predispone a la manifestación de su identificación étnica en la interacción con el endogrupo dominante. Cuando facilite la conciliación con sus creencias y sus intereses, la "nueva" identidad étnica se hará evidente; cuando los obstaculice, quedará latente.

\section{Conclusiones}

En el análisis de las historias de los migrantes de retorno nayaritas queda de manifiesto que el estudio de las creencias y actitudes linguísticas, implícitas en las argumentaciones narrativas de los migrantes retornados, es un eficaz instrumento para analizar los contenidos más frecuentes y significativos en los discursos sobre la identidad y las actitudes lingüísticas de los migrantes de retorno, entre los que destacan:

- El aprendizaje del inglés, con escolaridad o sin ella, como instrumento que permite la movilidad social de los migrantes, y como proceso de adquisición lingüística cualitativamente diferente al proceso de aprendizaje de la lengua materna, el español. 
- El desarrollo y mantenimiento del español en los espacios afectivos como símbolo de identificación y referente cultural, en oposición a la mezcla linguística con el inglés.

- La discriminación y normatividad con respecto al español, como indicadores del "hablar bien" la lengua de su país de origen.

En resumen, la construcción de identidades de los migrantes retornados es un proceso complejo donde las culturas que se encuentran -la de "allá" y la de "aquí"- no son ni homogéneas ni esenciales, de la misma forma que las identidades que se construyen en el espacio de encuentro son múltiples y contradictorias. Este trabajo aspira a convertirse en un instrumento que ayude a comprender y manejar esa diversidad.

\section{Referencias bibliográficas}

Ajzen, Icek .(1988). Attitudes, Personality and Behaviour, Open University Press, Milton Keynes. Bajtín, Mijail ([1979] 1982). Estética de la creación verbal, Siglo xxI, México.

Baker, Collin .(1992). Attitudes and Language, Multilingual Matters, Clevedon.

Chafe, Wallace. (1980). "The deployment of consciousness in the production of a narrative", en Wallace Chafe (ed.), The Pear Stories: Cognitive, Cultural and Linguistic Aspect of Narrative Production, Ablex, Norwood, NJ, pp. 9-50.

Coupland, Nikolas, Peter Garret y Angie Williams. (2005). Narrative demands, cultural performance and evaluation: Teenage boys' stories for their age-peers. En: Joanna Thornborrow y Jennifer Cates (eds.), The Sociolinguistics of Narrative, John Benjamins, AmsterdamPhiladelphia, pp. 67-88.

Fishbein, Martin (1966): The relationships between beliefs, attitudes and behavior. En: S. Feldman (ed.), Cognitive Consistency, Academic Press, New York, pp. 199-223.

Fishman, Joshua y Rebecca Agheyisi. (1970). Language attitude studies. En: Anthropological Linguistics, 12, pp. 137-157.

Garfinkel, Harold. ([1968] 2006). Estudios en Etnometodología, Anthropos, Barcelona.

Giles, Howard y Patricia Johnson. (1981). The role of language in ethnic group relations. En: J. Turner y H. Giles (eds.), Intergroup Behavior, University of Chicago Press, Chicago, pp. 199-243. 
(1987). Ethnolinguistic identity theory: A social psychological approach to language maintenance. En: International Journal of the Sociology of Language, 68, pp. 69-91.

Gumperz, John y Jenny Cook-Gumperz. (1982). Introduction: language and the communication of social identity. En: J. Gumperz (ed.), Language and Social Identity, Cambridge University Press, Cambridge, pp. 1-21.

Haarmann, Harald. (1986). Language in Ethnicity, Monton de Gruyter, Berlin.

Labov, William. ([1972] 1984): Modelos Sociolingüísticos, Cátedra, Madrid.

Lambert, William y Wallace Lambert. (1964). Social Psychology, Prentice-Hall, Englewood.

López Morales, Humberto. (1989). Sociolingüística, Gredos, Madrid.

Luna, Antonio. (2002). La frontera entre México y Estados Unidos: sociedad, cultura y tradición política. En: M. Gras, E. Martinell y A. Torres (eds. y coords.), Fronteras. Lengua, cultura e identidad, Institut Català de Cooperació Iberoamericana, Barcelona, pp. 248-263.

Mejía Navarrete, Julio. (2004). Sobre la investigación cualitativa. Nuevos conceptos y campos de desarrollo. En: Investigaciones Sociales, 7, Lima, pp. 277-299.

Portes, Alejandro y Lingxin Hao. (2001. E pluribus unum: Bilingüismo y pérdida de la segunda lengua en la segunda generación. En: Revista de Occidente, 2001, pp. 58-81.

Quintero Carrillo, José Luis. (2010). Las narrativas de frontera: la construcción del héroe en las historias de vida de los migrantes de retorno de Colima, México. En: Llengua, Societat i Comunicació, 8, pp. 83-92.

Silva-Corvalán, Carmen. (2000). La situación del español en Estados Unidos. En: El español en el mundo. Anuario del Instituto Cervantes, pp. 65-116.

(2001): Sociolingüística y pragmática del español, Georgetown University Press, Washington

Tajeel, Henri. (1974). Social identity and intergroup behavior. En: Social Science Information, 13, pp. 65-93.

([1981] 1984): Grupos humanos y categorías sociales, Herder, Barcelona. 
José Luis Quintero Carrillo

Apéndice

\section{Convenciones de transcripción}

Enunciados exclamativos ¡!

Enunciados interrogativos i?

Mayúsculas Inicial de nombres propios y siglas

Alargamiento ::

Risas@@@

Pausa

breve /

mediana //

Solapamiento [texto afectado]

Citas textuales y estilo directo "texto afectado"

Segunda lengua $\{($ L2) texto afectado $\}$

Palabra cortada -

Fragmento ininteligible xxx

Comentario del transcriptor (comentario) 